\title{
The Development and Countermeasures of Small and Medium-Sized Enterprise’s B2B E-commerce
}

\author{
SUN Liu \\ Jinan University, Jinan, China
}

\begin{abstract}
This paper firstly introduces the E-commerce and deeply explores current status of Chinese B2B E-commerce and problems existing in small and medium-sized enterprises. Secondly, based on the study of the E-commerce, the author studies successful business model of Alibaba and Made-in-China. Finally, according to Alibaba's and Made-in-China's successful business model experience, the author reflects problems in the process of development of small and medium-sized enterprises, and then the author puts forward the countermeasures of various issues.
\end{abstract}

Keywords: E-commerce, small and medium-sized enterprises, countermeasures

\section{Introduction}

In the 21st century, with the emerging information and communication technologies, one commercial model called Electronic Commerce (or E-commerce for short) has created a new economy model. With the booming of globalization and information technology, more and more enterprises begin to set foot in the E-commerce. In this process, small and medium-sized enterprises face many problems and challenges owing to the relatively small size and weakness. How to deal with problems and how to promote E-commerce trade growth are worth to be concerned.

\section{SME's Development of B2B E-commerce}

\section{General Introduction of E-commerce and B2B}

It is believed that E-commerce becomes a common practice in foreign trade. Nevertheless, no one can give an exact definition of E-commerce (TAN, XIE, \& Li, 2010, p. 6). It is generally defined as the sales aspect of E-business, because it also includes the exchange of data to facilitate the financing and payments. Besides, E-commerce is the exchange of products and services between five broad parties over the Internet. As a result, there are five models of E-commerce (see Table 1).

Table 1

Five Models of E-commerce

\begin{tabular}{lll}
\hline Name & Content & Cases \\
\hline B2B & Between businesses and businesses & Alibaba.com and Made-in-China.com \\
B2C & Between businesses and consumers & Retail businesses such as Amazon.cn and Tesco.com \\
C2C & Between consumers and consumers & Ebay and Taobao \\
B2G & Between businesses and governments & Company electronic customs, tax, and government online purchase \\
C2G & Between consumers and governments & Personal online declaration and pay taxes \\
\hline
\end{tabular}

SUN Liu, Undergraduate, School of Economics, Jinan University. 
In this chart, it can be showed that B2B and B2C are the most common models which are related to businesses in China. Business-to-business (B2B) refers to a wide range of online commerce transactions or business activities for products and services between businesses, such as between a manufacturer and a wholesaler, or between a wholesaler and a retailer.

\section{The Current Status of Chinese B2B E-commerce}

Generally speaking, the overall situation of E-commerce is optimistic. In order to elaborate the circumstance of B2B E-commerce, five aspects are proposed: transaction scale, enterprises scale, profit amount, market share, and information.

According to the Chinese E-commerce market report in 2014, market scale was about 13.4 trillion yuan, among which B2B reached 10 trillion Yuan, which increased 22\% as against that of 2013. B2B platform in 2014 has decreased as against that of 2013. There are two aspects reasons: on the one hand, due to the economic recession at home and abroad; on the other hand, owing to the competitive market and industry. Affected by national macroeconomic policies and diversified service provided by B2B service companies, total amount reached 255 hundreds of millions, a 24.4\% increase over 2013. In the year of 2014, B2B E-commerce service provider revenues (including the off-line service revenue), Alibaba ranked first in market share of 38.9\%, decreased by $5.6 \%$ compared with last year. Information provided by the seller without any structured treatment leads it pretty difficult for buyers to choose products. Buyers are always thoughtful when changing suppliers. Careful discussion and field inspection are often used. In the present stage of B2B, each message you find from the suppliers is independent, in other words, buyers must go through several rounds of consultation, then enter to next step. That is very inefficient.

B2B is a new kind of business model in economy. Compared with traditional business activities, B2B has three advantages. First of all, it takes much lower cost in exchange of information between buyers and sellers. The traditional business uses the telephone, telegraph, fax, and other outdated tools, which cannot be placed in the same category with Internet. Secondly, with the booming of the internet and information technology, the methods of communication among human society have broken the limitation of time and space. Thirdly, in contrast to TV, magazine, bulletin board, and other advertisements, B2B is more effective in terms of publishing information and promoting image of enterprise (MA, 2011, p. 185).

\section{Problems Exist in SMEs}

B2B marketing is not a perfect industry, but the main arguments against B2B marketing, like not original, full of competition, and having boring products, are also the areas where a company can stand out most online. The following are some of the biggest problems in B2B marketing.

According to marketing software data, "61 percent of global Internet users search products online" and according to Google.com, "business buyers do not contact suppliers directly until $57 \%$ of the process is finished”. So what does that mean about awareness for your international business? People are ignoring the overflow of aggressive marketing and sales messages in their daily lives and are instead looking for message on their own. Many, if not most, B2B buyers lack enough knowledge on what they are buying. But business men are professors on what they sell. The resulting script is the perfect opportunity for prospect education. Years of experience among the merchandiser, project managers, and executives within company provide more than enough opportunity not only to convince prospects to buy, but to help them through that purchasing process. 
Business company can provide sales and build a trusting and loyal customer group by providing education on goods, services, and the benefits they deliver.

There are so many B2B enterprises which limit their general project to trade leads, for example, trade shows and meet-and-greet. Sales person can only be in one place at a time. Personal relationships matters are as well. This is especially true in the B2B world. But consider this: Not every personal relationship has to start in person. Business company website has the powerful ability to start communications with prospects while sales person is talking to others personally or over the phone. Just as a sales person catches a business card following a fresh trade show coming across with a quality prospect, company website must be equipped to collect names, phone numbers, and email addresses from its visitors before they go away and disappear forever. So the company takes part in more qualified B2B trade leads is very important (MA, 2011, p. 200).

But B2B companies will sink 15,000 dollars into a trade show in one month and 5,000 dollars into a bulletin board advertisement the next without blinking. Traditional marketing channels or methods certainly have their place in the mix. They target a niche market after all. But experience has shown that the cost in each lead acquired through traditional channels can be two to three times as high as those acquired through an online.

The information the company finds on a true business card is enough to make a sales call. But what if you also know what product or service pages on your website a consumer has visited and how many times that person has returned to those particular pages? What if you know how engaged he has been with your marketing emails? Even better, what if that person has already implied the business problems he sees on a regular platform that your company specializes in solving? Today, the smartest B2B marketers equip themselves with lead intelligence collected through their websites. And they use this message to divide their leads not only by industry or science, but also by stage in the purchasing process and likelihood to close as a customer. The results are better-prepped salesmen and get more successful sales calls.

Prospects do not desire repeated sales pitches from the same salesmen. But they do desire repeated fresh resources that help them to overcome challenges and do their jobs better. So instead of trying to sell audience repeatedly what they are not yet ready to buy, stay in mind by helping address their business challenges. Email is your platform for nurturing leads with consistent, automated touch points based on who they are and what needs they have. While sales team is selling, these automatic campaigns run in the background.

Despite the economic slowdown, global revenues from E-commerce should continue to grow strongly. B2B growth accounts for the most significant element of E-commerce revenues rather than business to consumers. However, B2B E-commerce transaction risks are increasing. Honesty and security problems have become an obstacle in B2B developing process. And there are four aspects about credit problem. Firstly, messages are not complete for transaction main body. Compared with traditional trade model, E-commerce is a kind of virtual economic activities, so unknown messages of main body are prone to occur. Secondly, because many of the B2B websites use membership system, thus members' identity is lack of authority. Thirdly, for authentication, E-commerce has not formed a standardized mechanism, so the verification result cannot be shared between different B2B website. Lastly, the quality of uses influence the rate of successful transaction, but the reality is that users only can enjoy membership services within a certain period of time (JU, 2014, p. 42-43).

\section{The Study of Two Typical B2B Models}

\section{E-commerce Giant Alibaba}

Alibaba is a well-known company in every Chinese E-commerce space founded by Jack MA and 17 other 
co-founders. And it is one of the most famous B2B platforms. For an export enterprise just starting out to do business E-commerce, Alibaba provides a relatively comprehensive one-stop platform service. With a lot of advertising activities at home and abroad in the past few years, Alibaba already got great popularity and reputation in the B2B industry, which attracted steady website traffic and purchasing groups.

Alibaba ranked 47, which becomes the pioneer both in global and Chinese site according to Alexa.com Traffic Ranks, let alone in B2B website. When it comes to search traffic, there are approximately 10 percent to 20 percent visits from search engines and there are about 26.92 percent of top keywords are used on Alibaba. Obviously, Alibaba has been the giant of B2B E-commerce.

\section{The B2B Developing Process of Alibaba}

In December, 1998, Jack MA and 17 other co-founders launched their first online marketplace, named “Alibaba Online”. From 1999 to 2000, Alibaba Group raised a total of 25 million US dollars from Softbank, Goldman Sachs, and some other institutions. In December, 2001, Alibaba achieved profitability. In October, 2005, Alibaba Group took charge of the operation of Chinese Yahoo and took it as part of its strategic partnership. In November, 2007, Alibaba.com was successfully listed on the Hong Kong Stock Exchange.

In September, 2008, Alibaba Group Research and Development Institute were established. In December, 2008, Alibaba group announced that all Alibaba group free websites would be stopped on January 1, 2009. In September, 2009, Alibaba Group founded Alibaba Cloud Computing in conjunction with its 10-year anniversary. In March, 2014, Alibaba group claimed that it would set out for the process of filing for an initial public offering in the United States. On May 6, 2014, Alibaba Group filed registration documents to go public in the US, which may be one of the biggest initial public offerings in American history.

\section{The Successful B2B Model of Alibaba}

Alibaba group consists of B2B, C2C, and Alipay service. One of its core businesses is the "China Supplier" service committed to the international export enterprises. According to Alibaba's third quarter financial report released in November, 2009, its registered users both at home and abroad at that time reached 45.27 million, with 34.79 million from around China and 10.48 million from overseas.

Alibaba B2B model protects its business from logistics chain. In other words, it provides sales support as a third party for suppliers especially for small and medium-sized enterprises. As we know, the only thing provided by Alibaba is a platform which includes mass transaction information, rather than business agreement.

Alibaba's success is not only the result of its structure, but also driving force of business strategy (YANG, QIAN, \& ZHANG, 2009, p. 20). First of all, it is "brand strategy". After the establishment of website, Alibaba makes full use of funds taken from venture capital to place advertisement on famous media such as CNN (Cable News Network), CNBC (Consumer News and Business Channel), and CCTV (China Central Television) both at home and abroad. This effective strategy successfully builds its brand, which greatly attracts purchase party in Europe and America. Besides, Alibaba's biggest IPO (Initial Public Offerings) in American history attracted the great attention of global business people.

Second, it is "technology and talent strategy". For an E-commerce enterprise, security, stability, and convenience of platform are the key points about users' experience. Alibaba hired technology developers from yahoo as their CTO (Chief Technology Officer), and searched talents within the scope of globe in order to make sure of security and stability of website. In 2005, Alibaba purchased yahoo China as its subsidiary, therefore, excellent search technology could be applied to the platform. These two strategies are the key points 
in the Alibaba’s successful B2B model.

\section{Focus Technology Made-in-China}

Established in 1996 by Shen Jinhua, Made-in-China dedicated it to providing E-commerce service to China's international trade enterprises. According to the Prospectus released on November 18, 2009 by Focus Technology, the official network operator of Made-in-china.com, by June 30, 2009, registered members at the E-commerce platform of made-in-China.com scored 3,617 thousand, including 10,000 registered paying members. And this website has already posted over 12.10 million effective products and market information.

As currently Made-in-China has overseas websites, its international influence is relatively. But as the websites has been focusing on the promotion of products made in China for a longtime, it still has certain influence among the overseas buyers group. Owing to SMEs (small and medium-sized enterprises) with limited capital budget in advantageous industries and relatively low pricing mechanisms, this website is a great choice.

How popular is Made-in-China.com? The following Figure 1 can provide an exact view of its popularity.

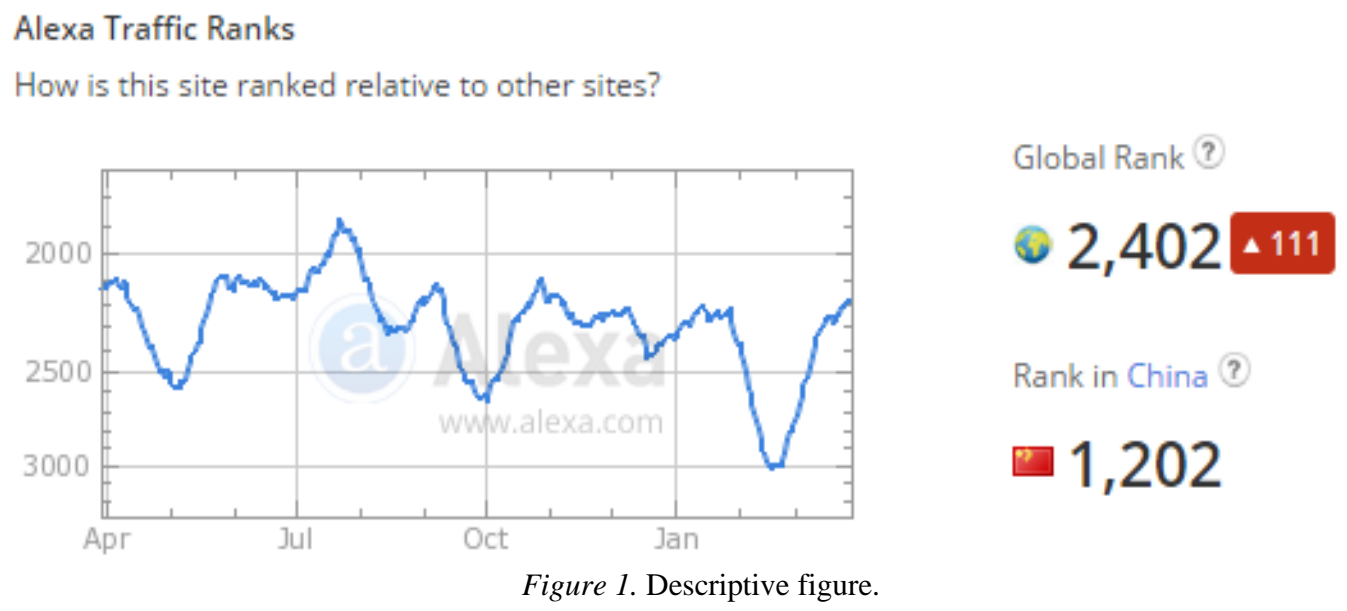

From the figure above, it can be showed that Made-in-China ranked 2,402 in global websites, and 1,202 in China. Even if it was unsatisfactory to the enterprise compared with Alibaba, it picked up speed according to the search traffic data. And there are 17.7 percent of top keywords from the search engines on Made-in-China which also accounts for big part in B2B website.

\section{The B2B Developing Process of Made-in-China}

In 1996, Focus Technology Development Company Limited was established in Nanjing, China, committed to provide internet application service to small and medium-sized enterprises. In 1998, Made-in-China was officially founded to provide efficient and reliable E-commerce services to the international trade of all parties. In 2000, the Focus issued a joint Internet model where domestic and international stations can run together. “Top Rank” service came online in 2002, which won the reputation from all parties and became key import and export channel to the east and south coast of the country's enterprises. Made-in-China was awarded as "the most influential Chinese foreign trade enterprises" in the first annual meeting of China's foreign trade in 2006. On the occasion of the 10th anniversary, Made-in-China released a new version of the website to provide China suppliers with a more comprehensive, more convenient, and more personalized service. In December 9, 2009, Focus Technology Company Limited was listed in Shenzhen A shares market. 
As the one of the popular international E-commerce platform, Made-in-China creates unlimited opportunities for Chinese enterprises and global buyers, which opens a convenient door for prosperous trade.

\section{The Successful B2B Model of Made-in-China}

Over the past decade, Alibaba had absolute authority over B2B E-commerce, while Made-in-China gained the first place with its splendid modesty. It is believed that Made-in-China is famous for its successful business model which is named professional subdivision and international service. As we know, its advantages are mainly concentrated in the clothing, handicrafts, transport, machinery, and other industries.

From 1996 to 1999, business and internet activities swept the globe. The most valuable thing to point out is that its role acts as integrated service provider. On the occasion of 107th Canton Fair, Made-in-China held international buyers meeting with British and Brazil Chamber of Commerce and chose quality suppliers among members which won the great success in this purchase session. It is not the first time for Made-in-China to hold such kind of offline activities, and Made-in-China is not only an internet company or third-party B2B platform, but also an integrated service provider for SMEs, as the president of Focus Technology said. To focus on customer's interest is the trump card as well as the successful model of Made-in-China.

\section{Countermeasures to SMEs’ Problems}

E-commerce is not a simple proposition, as we all know, the volume of B2B business is a considerable force in China's business world. Four-fifths of the China's companies are small and medium-sized which in turn produce more than four-fifths of the volume of China's business. So it requires an entire infrastructure of support systems, including secure payment, delivery logistics, cooperation with banks, and government regulations. In response to these problems, we show the following several countermeasures.

Enterprises, especially non-IT enterprises should take actively action to improve the understanding of electronic commerce and to propose appropriate plans. It is important that enterprises exist leaders or executives who attach great importance to E-commerce businesses. If business leaders put real importance to the development of E-commerce in heart, then related resources can be integrated, and this will promote the development of E-commerce greatly (WANG, 2002, p. 161).

Internet resources are very rich; it can provide a variety of information to the visitor. All companies must not only pay full attention to their own release of information, but also need to focus on useful information to them. For example, companies can go through the supply chain business, find the supply and demand information. Take a look at a competitor's site to know their dynamics. What is more, it can also visit some of the relevant government website for some latest policy or government procurement information. In addition, companies can also make full use of public e-mail to collect information (JU, 2014, p. 41).

Set up an official website, and do well in maintenance. There is no limit and border on internet; therefore, it provides enterprises with ideal low-cost information and distribution channels. A wide range of corporate website is submitted to search engines, thus there is rapidly increasing rate of the site visit, no wonder it is one of the best way to expand the enterprise market visibility. At this stage, corporate website should be noted the content provided. Domain name should be simple and easy to remember. Besides, as much as information of products or services should be given including photos, words, and even videos. For some smaller companies, they can also register a professional website or business website. Because this type of site visits rate is focused, they maybe often receive good results (NU, 2010, p. 288). 
Mobile apps are becoming more widely used to help businesses run their operations and better serve customers, but companies need to take a good look at their business processes and work flows to identify the apps that will generate the most value. As more companies accept the idea of using mobile apps designed for companies, which allow business people to do a part or all of their works from a smart phone or tablet, it is necessary to identify which apps will bring the most value to the organization.

With the foreign trade E-commerce development, there are activities which do harm to network honesty and security. Thus operating professional B2B website and investigating member of website is prerequisite task. This initiative is beneficial for establishing brand credibility and reliability to customers. For example, Alibaba credit protection service launched on December 11, 2015. The purpose of establishing these regulations is to protect the legitimate interests of users of the Alibaba international platform. From March 1st to March 4th, 2015, Alibaba promoted the credit protection service to US buyers in the ASD exhibition. During this period, Alibaba did a survey about credit protection service, which showed that $88 \%$ of the respondents would like to use credit production service in the next round of purchase (FAN, 2014, p. 21).

\section{Conclusion and Prospect}

This paper analyzes the domestic small and medium-sized enterprises’ B2B E-commerce development, including the main problems encountered in the process of development and solutions to solve these problems. There is a big difference between large and small medium-sized enterprises' E-commerce developing model. Development is especially difficult for SMEs (small and medium-sized enterprises).

\section{References}

FAN, P. (2014). The B2B E-commerce credit risk control research in China. Chengdu: Southwestern University of Finance and Economics.

JU, D. S. (2014). Study on the problems and countermeasures of China's small and medium-sized foreign trade enterprises application of B2B E-commerce. Chengdu: Southwest Jiaotong University.

MA, Y. J. (2011). The problems and countermeasures of the mode of B2B E-commerce in China. Science and Technology Information, 27, 185-233.

NU, W. S. (2010). On development and countermeasures of E-commerce of SME in China. Management and Technology of SME, 9, 287-288.

NIE, L. H. (2014). The features and tendency of the development of E-commerce in China. China Business and Market, 6, 97-101.

TAN, X. L, XIE, W., \& LI P. X. (2010). Classification, application and innovation on E-commerce model. Technology Economics, 10, 6-7.

WANG, W. H. (2002). Strategy research for E-business development in China. Hangzhou: Zhejiang University.

YANG, A. H., QIAN, X. H., \& ZHANG, Q. (2009). Study on B2B model of Alibaba. Consume Guide, 5, 20-21. 